University of Wollongong

Research Online

Faculty of Engineering and Information

Faculty of Engineering and Information

Sciences - Papers: Part A

Sciences

$1-1-2012$

\title{
Reinforcement with graphene nanosheets in aluminum matrix composites
}

Jingyue Wang

Shanghai Jiao Tong University

Zhiqiang Li

Shanghai Jiao Tong University

Genlian Fan

Shanghai Jiao Tong University

H H Pang

Shanghai Jiao Tong University

Zhixin Chen

University of Wollongong, zchen@uow.edu.au

See next page for additional authors

Follow this and additional works at: https://ro.uow.edu.au/eispapers

Research Online is the open access institutional repository for the University of Wollongong. For further information contact the UOW Library: research-pubs@uow.edu.au 


\title{
Reinforcement with graphene nanosheets in aluminum matrix composites
}

\author{
Abstract \\ Graphene has a high fracture strength of $125 \mathrm{GPa}$, making it an ideal reinforcement for composite \\ materials. Aluminum composites reinforced with graphene nanosheets (GNSs) were fabricated for the \\ first time through a feasible methodology based on flake powder metallurgy. The tensile strength of 249 \\ MPa was achieved in the Al composite reinforced with only $0.3 \mathrm{wt} . \%$ GNSs, which is $62 \%$ enhancement \\ over the unreinforced Al matrix. The relevant strengthening mechanisms involved in the GNS/AI \\ composites were discussed along with experimental procedure.
}

\section{Keywords}

nanosheets, composites, reinforcement, matrix, graphene, aluminum

\section{Publication Details}

Wang, J., Li, Z., Fan, G., Pang, H., Chen, Z. \& Zhang, D. (2012). Reinforcement with graphene nanosheets in aluminum matrix composites. Scripta Materialia, 66 (8), 594-597.

\section{Authors}

Jingyue Wang, Zhiqiang Li, Genlian Fan, H H Pang, Zhixin Chen, and Di Zhang 


\title{
Reinforcement with graphene nanosheets in aluminum matrix composites
}

\author{
Jingyue Wang, ${ }^{\mathrm{a}}$ Zhiqiang Li, ${ }^{\mathrm{a}, *}$ Genlian Fan, ${ }^{\mathrm{a}}$ Huanhuan Pan, ${ }^{\mathrm{a}}$ Zhixin Chen ${ }^{\mathrm{b}}$ \\ and Di Zhang ${ }^{a, *}$ \\ ${ }^{a}$ State Key Laboratory of Metal Matrix Composites, Shanghai Jiao Tong University, Shanghai 200240, China \\ ${ }^{\mathrm{b}}$ The Faculty of Engineering, University of Wollongong, Wollongong, NSW 2522, Australia
}

Received 12 November 2011; revised 3 January 2012; accepted 9 January 2012

Available online 16 January 2012

\begin{abstract}
Graphene has a high fracture strength of $125 \mathrm{GPa}$, making it an ideal reinforcement for composite materials. Aluminum composites reinforced with graphene nanosheets (GNSs) were fabricated for the first time through a feasible methodology based on flake powder metallurgy. The tensile strength of $249 \mathrm{MPa}$ was achieved in the Al composite reinforced with only $0.3 \mathrm{wt} . \% \mathrm{GNSs}$, which is $62 \%$ enhancement over the unreinforced $\mathrm{Al}$ matrix. The relevant strengthening mechanisms involved in the GNS/Al composites were discussed along with experimental procedure.

(c) 2012 Acta Materialia Inc. Published by Elsevier Ltd. All rights reserved.
\end{abstract}

Keywords: Metal matrix composites; Graphene nanosheets; Flake powder metallurgy; Mechanical properties; Strengthening mechanism

Graphene, as the perfect two-dimensional (2-D) lattice of $s p 2$-bonded carbon atoms [1,2], has recently attracted tremendous attention due to its excellent properties, such as high Young's modulus (1 TPa) [3], high fracture strength (125 GPa) [3], extreme thermal conductivity $\left(5000 \mathrm{~W} \mathrm{~m}^{-1} \mathrm{~K}^{-1}\right)$ [4] and super charge-carrier mobility $\left(200,000 \mathrm{~cm}^{2} \mathrm{~V}^{-1} \mathrm{~s}^{-1}\right)$ [5]. Graphene nanosheets (GNSs) composed of a few graphene layers possess properties similar to that of single-layer graphene but are much easier to produce and handle. It has been supposed that GNSs may significantly outperform carbon nanotubes (CNTs) and have great potential in the electronic and composite fields as a superior electronic component and ideal reinforcement. Therefore the research and development of GNS-based nanocomposites is an important factor in the practical application of graphene [6].

On the other hand, owing to their higher strength combined with lighter weight beyond conventional metals and alloys, metal matrix composites (MMCs) have been extensively applied in the automobile, aerospace and electronic industries [6]. To meet ever increasing demands for structural strength and energy efficiency, CNT-reinforced aluminum composites (CNT/Al) have been investigated extensively and intensively over the

\footnotetext{
* Corresponding authors. Tel.: +86 213420 2584; fax: +86 213420 3913; e-mail addresses: lizhq@sjtu.edu.cn; zhangdi@sjtu.edu.cn
}

past decade [7]. Though many improvements have been made, it may still be a long time until CNT/Al composites are used in practical applications. The main challenge lies in getting CNTs to disperse uniformly in the aluminum matrix without damaging the structure of the CNTs. Compared with CNTs, GNSs with a platelet shape are easier to handle and disperse in solvents or all kinds of matrices. Therefore, we are confident that GNS/Al has a good potential to replace CNT/Al as a candidate for the next-generation MMCs.

However, in comparison with polymers and ceramics, GNS-based MMCs have been little researched. Most of the existing reports focus on the deposition of nanoparticles of noble metals and oxides, like $\mathrm{Au}, \mathrm{Pt}, \mathrm{Ag}$ and $\mathrm{TiO}_{2}$, on the surface of GNSs to impart new functionalities, such as catalytic, energy storage, photocatalytic, sensory and optoelectronic [8-10]. Several papers have recently been published on simulation of the GNS/metal $(\mathrm{Al}, \mathrm{Cu}, \mathrm{Ni})$ interfacial structure and prediction of the mechanical properties of GNS/A1 [11-13]. However, to our knowledge, there has been no report on the fabrication and actual properties of bulk GNS-based MMCs. In this work, we explored a novel methodology based on flake powder metallurgy (Flake PM) [14] to fabricate bulk GNS/Al composites. The mechanical properties of the bulk GNS/Al composites were tested and the relevant strengthening mechanisms of GNSs discussed based on the primary experimental evidences. 
The technical challenges of synthesizing GNS/Al composites are similar to those of CNT/Al composites. To use the full potential of GNSs as reinforcement, a feasible pathway must be found to achieve homogeneous distribution of GNSs in the Al matrix while maintaining the structural integrity of the GNSs. Fortunately, the Flake PM route, recently developed for the fabrication of CNT/A1 composites, has also proved applicable to GNS/Al composites. In this method, graphene oxide (GO) nanosheets rather than GNSs were used as the raw material because there are many hydroxyl and epoxy groups on the surface of GO, which make it much easier to disperse in solvents and form more stable solutions than graphene $[15,16]$. The GO nanosheets were first adsorbed onto polyvinyl alcohol (PVA)-treated Al flakes and then reduced to GNSs by rapid heating to a high temperature $[17,18]$. Though there were some residual oxygen and point defects left on the surface of the reduced GO, this method enabled effective and uniform dispersion of GNSs in the flaky Al powder and the final GNS/Al composites. Powder compacting, sintering and hot extrusion were applied to consolidate the GNS-adsorbed Al flakes into bulk composites. The tensile strength increased from 154 to $249 \mathrm{MPa}$ by the addition of only $0.3 \mathrm{wt} \%$ GNSs and a uniform elongation of $13 \%$ was retained, which demonstrates that GNSs are very promising as an effective reinforcement in an $\mathrm{Al}$ matrix composite, and our methodology is a feasible and successful way to fabricate GNS-based metal matrix composites.

Four steps are involved in the novel methodology based on Flake PM:

(1) Preparation of GO aqueous dispersion. Graphite oxide ( $0.1 \mathrm{~g}, 95 \%$ in purity) was added to deionized water $(200 \mathrm{ml})$ and the solution was ultrasonicated until it became brown, which implied that the GO had been exfoliated into several-layered or even single-layered nanosheets.

(2) Preparation of Al flakes and surface modification. The spherical Al powder (about $10 \mu \mathrm{m}$ in diameter, $99 \%$ in purity) were transformed into $2 \mu \mathrm{m}$ thick Al flakes through ball milling in an attritor at $325 \mathrm{rpm}$. The Al flakes were then treated in $3 \mathrm{wt} . \%$ PVA aqueous solution to introduce a hydrophilic PVA membrane on the surface of the Al flakes. Details of the surface modification have been reported elsewhere [19].

(3) Adsorption and reduction of GO nanosheets. The PVA-modified Al flakes were added to deionized water to form a powder slurry, then the GO aqueous dispersion was added drop by drop. The mixed slurry was mechanically stirred until its color changed from brown to transparent, before being filtered and rinsed with deionized water to obtain GO/Al composite powders. The GO/Al composite powders were heated to $550{ }^{\circ} \mathrm{C}$ at a heating rate of $40{ }^{\circ} \mathrm{C} \mathrm{min}{ }^{-1}$ and kept in flowing Ar for $2 \mathrm{~h}$ to decompose the PVA and reduce the GO nanosheets to GNSs, until finally GNS/Al composite powders were obtained.

(4) Compacting and consolidation of GNS/Al composite powders. The GNS/Al composite powders were first compacted into $\Phi 40 \times 30 \mathrm{~mm}$ billets, which were consolidated by sintering in an $\mathrm{Ar}$ atmosphere at $580^{\circ} \mathrm{C}$ for $2 \mathrm{~h}$, followed by hot extrusion at $440{ }^{\circ} \mathrm{C}$ with an extrusion ratio of 20:1. For comparison, a pure Al specimen was also prepared by the same process using flaky Al powder.

Tensile specimens of $5 \mathrm{~mm}$ diameter and $25 \mathrm{~mm}$ gauge length were machined from the extruded rods, and tensile test was carried out in a Shimadzu Autograph AG-I (50 $\mathrm{KN}$ ) at an initial strain rate of $1 \times 10^{-3} \mathrm{~s}^{-1}$ at ambient temperature. The morphology and structure of GO were characterized by transmission electron microscopy (TEM; JEOL JEM-2010) and atomic force microscopy (AFM; E-Sweep). The adsorption of GO nanosheets onto the surface of flaky Al powder was analyzed by Raman spectroscopy (Jobin-Yvon Labram 800), and the reduction of GO nanosheets into GNSs was characterized by Fourier transform infrared spectroscopy (FTIR; EQUINOX55). The morphology of the flaky Al and $\mathrm{GO} / \mathrm{Al}$ composite powders and the fracture surface of the GNS/Al composites were characterized by scanning electron microscopy (SEM; FEI SIRION 200). The grain size and dislocation density were evaluated using the Scherrer equation and the Dunn equation based on the X-ray diffraction (XRD; Rigaku D/max-2550/PC) with a $\mathrm{Cu} K \alpha$ radiation source.

As shown in Figure 1a, Al flakes had a 2-D planar morphology and an average thickness of about $2 \mu \mathrm{m}$. Figure $1 \mathrm{~b}$ is a typical TEM image of GO nanosheets suspended over a perforated carbon film covering a copper grid. The edges of the GO nanosheets were distinguishable and they should contain just a few layers. Wrinkles and folds were very evident on the surface of the GO nanosheets; these are characteristic of thin and 2-D GO. Figure 1c is an AFM image of GO nanosheets and Figure 1d is the corresponding depth profile along the line marked in Figure 1c. As can be seen, the thickness of the GO nanosheets was less than $1.5 \mathrm{~nm}$, indicating that there are no more than five graphene layers.

As shown in Figure 2a, b, the surface of the GO/Al composite powders had many wrinkles, while the surface

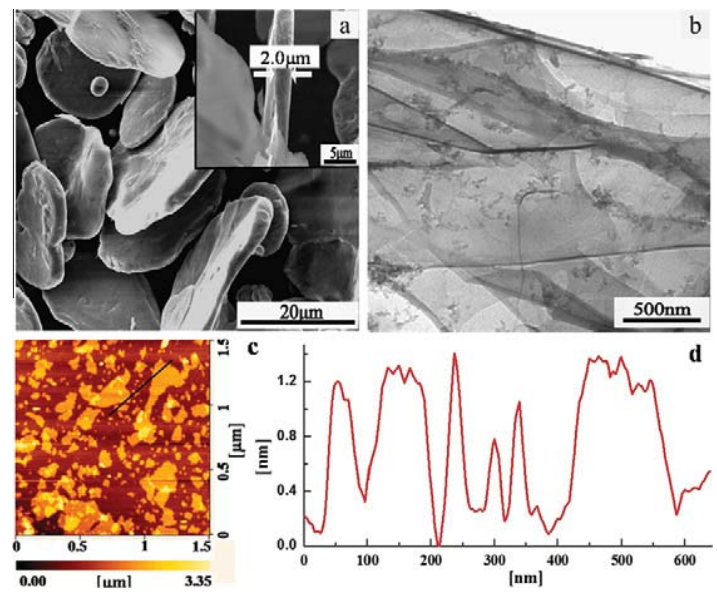

Figure 1. (a) SEM image of flaky Al powder; the inset shows the average thickness of the $\mathrm{Al}$ flakes; (b) TEM image of the GO nanosheets; (c) AFM image of the GO nanosheets; (d) depth profile of the line on the GO nanosheets in (c). 

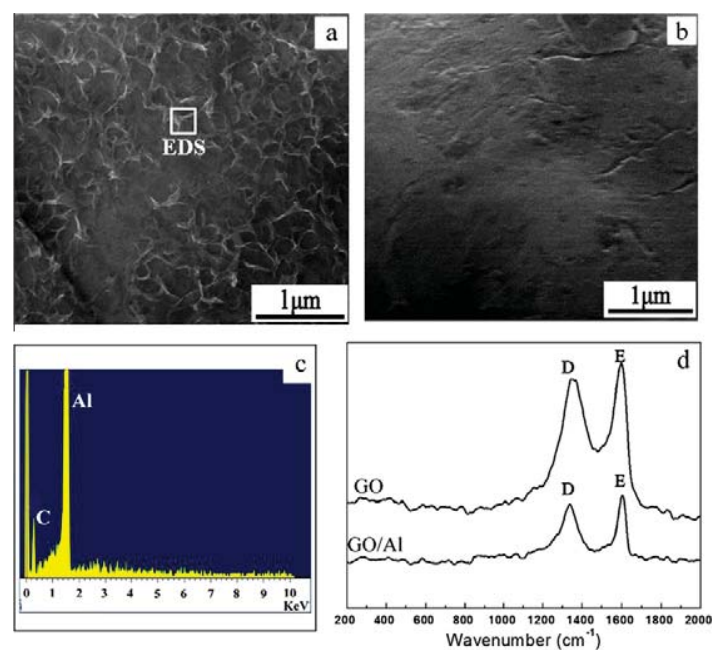

Figure 2. (a) SEM image of an Al flake surface with adsorbed GO nanosheets; (b) SEM image of an Al flake surface without GO nanosheets; (c) the EDS of the selected area in (a); (d) Raman spectra of $\mathrm{GO}$ powder and 0.3 wt. $\% \mathrm{GO} / \mathrm{Al}$ powders.

of the pure Al flakes was very smooth. As testified by many researchers, fine wrinkles such as those shown in Figure $2 \mathrm{a}$ are signs of homogeneous dispersion of GO nanosheets. It is believed that, in the present study, the shape compatibility of the Al flakes and GO nanosheets is crucial to achieve uniform dispersion.

EDS analysis (Fig. 2c) and Raman spectra (Fig. 2d) also supplied evidence of the adsorption of GO nanosheets by Al flakes. EDS analysis showed the existence of a carbonaceous composition in the $\mathrm{GO} / \mathrm{Al}$ composite powders, while the Raman spectra of the GO/Al composite powders showed a D band at $1348.8 \mathrm{~cm}^{-1}$ and a $\mathrm{G}$ band at $1594.9 \mathrm{~cm}^{-1}$, both of which are typical of pristine GO. It should be noted that the PVA membrane on the surface of the flaky Al played an important role in the adsorption of GO nanosheets. This is because the hydroxyl groups in PVA endowed Al with good water wettability and enabled a strong hydrogen-bonding interaction between $\mathrm{Al}$ and $\mathrm{GO}$, thus resulting in the uniform adsorption of the GO nanosheets onto the surface of the Al flakes.

As shown in Figure 3a, the main difference between graphene and GO was that there were many hydroxyl, carbonyl, carboxylic and epoxy groups on the surface of GO. Typical FTIR spectra of GO and reduced GO are given in Figure $3 \mathrm{~b}$. The most characteristic feature of $\mathrm{GO}$ is the broad, intense band of $\mathrm{O}-\mathrm{H}$ stretching vibration at $3350 \mathrm{~cm}^{-1}$, as well as the bands of $\mathrm{C}=\mathrm{O}$, $\mathrm{C}-\mathrm{OH}$ and $\mathrm{C}-\mathrm{O}$ stretching vibration respectively at 1725,1496 and $1205 \mathrm{~cm}^{-1}$. In the FTIR spectrum of reduced GO, the $\mathrm{O}-\mathrm{H}$ band shifted to $3644 \mathrm{~cm}^{-1}$, while the breadth and intensity decreased drastically. The bands of $\mathrm{C}-\mathrm{O}$ and $\mathrm{O}-\mathrm{H}$ stretching vibrations also disappeared, but a band of skeletal vibrations from the graphitic domains emerged at $1421 \mathrm{~cm}^{-1}$. Thus, FTIR spectroscopy provided convincing proof that GO nanosheets were effectively transformed to GNSs by thermal reduction.

Shown in Figure 4a are stress-strain curves of GNS/ Al composite and unreinforced pure Al. The GNS/Al
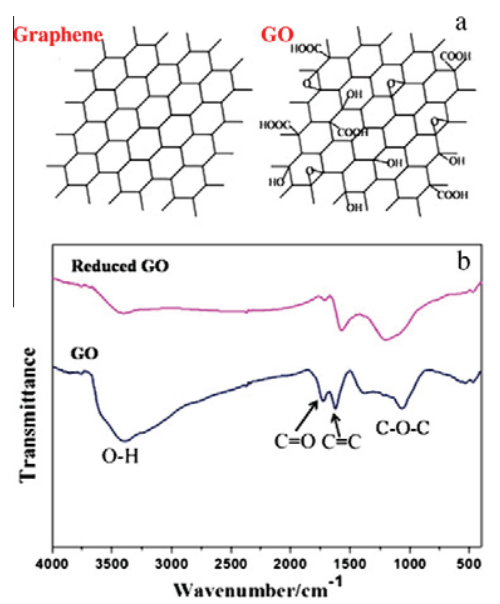

Figure 3. (a) Structure of the graphene and GO; (2) FTIR of the GO and reduced $\mathrm{GO}$ by rapid heating to $550{ }^{\circ} \mathrm{C}$ in a flowing $\mathrm{Ar}$ atmosphere.
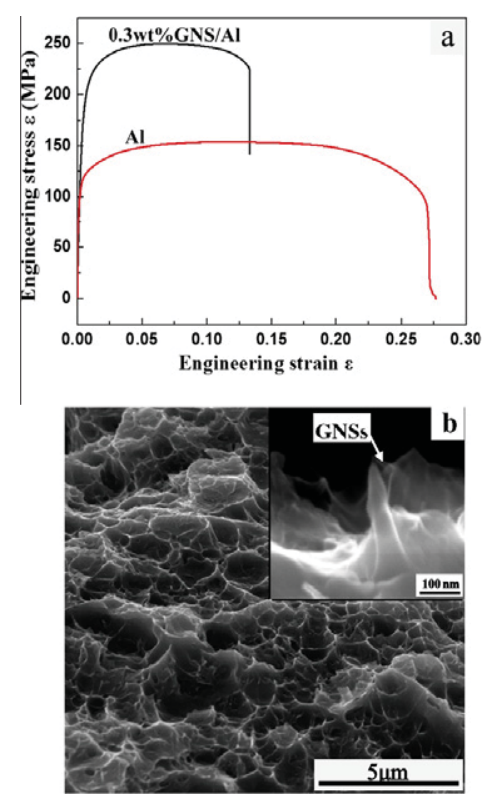

Figure 4. (a) Tensile properties of 0.3 wt. $\%$ GNS/Al composite and the corresponding flaky $\mathrm{Al}$ specimen; (b) fracture surface of $0.3 \mathrm{wt} . \%$ GNS/Al composite; the inset shows the GNSs pulled out.

composite exhibited a tensile strength of $249 \mathrm{MPa}$ with $13 \%$ elongation, which was a $62 \%$ improvement in tensile strength compared to that of unreinforced Al matrix (154 MPa). Considering that only 0.3 wt. $\%$ GNSs was added, the enhancement ratio of GNSs significantly exceeded that of any other reinforcements. These results demonstrate that GNSs have huge potential as the most ideal reinforcement in aluminum matrix composites.

Based on the fracture strength of a perfect singlelayer graphene (125 GPa [3]) and the rules of mixture, and assuming the alignment of all the GNSs along the tensile direction, an improvement in tensile strength as high as $500 \mathrm{MPa}$ can theoretically be expected from the addition of $0.3 \mathrm{wt} . \%$ (about 0.5 vol. $\%$ ) GNSs into an $\mathrm{Al}$ matrix. However, in the present study, the actual increment in the tensile strength was no more than $100 \mathrm{MPa}$, which is equivalent to only $20 \%$ of graphene's potential. This is a result of three main drawbacks. The 
first is that it was not single-layer graphene, but few-layered GNSs with residual groups due to incomplete reduction that were introduced into the composites, and had a fracture strength much lower than $125 \mathrm{GPa}$. Secondly, the out-of-plane strength of GNSs is much less than the in-plane strength, thus those GNSs not aligned along the tensile direction cannot reach their full potential. The third drawback is that the processing parameters, microstructure, interfacial reaction and bonding of the GNS/Al composite used were not optimized, leaving much room for improvement. As in the $\mathrm{CNT} / \mathrm{Al}$ composites [7], the possible formation of aluminum carbide $\left(\mathrm{Al}_{4} \mathrm{C}_{3}\right)$ at the $\mathrm{GNS} / \mathrm{Al}$ interface may also have a great effect on the strength enhancement.

To optimize the design and fabrication procedure of GNS/Al composite, it is important to understand the relevant strengthening mechanisms and the role of GNSs involved in GNS/Al composites. Theoretically, if they are uniformly dispersed and well bonded with Al matrix, GNSs could contribute to the strength enhancement through the following three mechanisms: grain size refinement, dislocation strengthening and stress transfer. First, GNSs were expected to impede the grain coarsening during thermal processing and impede the dislocation motion during plastic deformation, thus increasing the tensile strength of the Al matrix. Secondly, GNSs were also expected to undergo a substantial part of the mechanical load during plastic deformation. Based on the analysis of the XRD spectra, the average gain size and dislocation density of the GNS/Al composites are almost the same as those of the unreinforced $\mathrm{Al}$ matrix. The reason for this is that only a very small percentage of the matrix was affected by the GNSs because the thickness of the Al flakes used in the present study are a thousand times those of the GNSs. On the other hand, the stress transfer of the GNSs was clearly evidenced by the fracture morphology of GNS/Al composites, which displayed dimples that were elongated in the direction of loading and some GNSs were pulled out at the edges of the dimples (Fig. 4b and inset).

In summary, GNS/Al composite was successfully fabricated through a scalable process based on Flake PM, in which GNSs of no more than five graphene layers was uniformly introduced into an aluminum matrix. The composite with only $0.3 \mathrm{wt} . \%$ GNSs addition exhibited a tensile strength improvement of $62 \%$ over unreinforced matrix, as well as a uniform elongation well beyond the 5\% standard for engineering applications. Though not as good as theoretical expectations, the preliminary results achieved here demonstrate for the first time that graphene nanosheets can actually act as effective reinforcements in metal matrix composites, and stress transfer of GNSs is the main strengthening mechanism of the GNS/Al composites made. There is undoubtedly still a long way to go to achieve the full potential of GNSs as a reinforcement in metal matrix composites. Our future work will focus on the optimization of the processing parameters, microstructure, interfacial reaction and bonding of the GNS/Al composite, with the aim of clarifying the effects of Al flake thickness on the GNSs content and processing temperature/time on the interfacial reaction. Thus, further improvement in the mechanical properties could rationally be expected due to the synergistic action of all the three mechanisms: grain size refinement, dislocation strengthening and stress transfer.

The authors like to acknowledge the financial support of the National Basic Research Program (973 Program) (No. 2012CB619600), the National Natural Science Foundation (Nos. 51071100, 51131004, 50890174), the National High-Tech R\&D Program (863 Program) (No. SS2012AA030611), the International S\&T Cooperation Program (Nos. 2010DFA52550, 2009DFA52410) of China and the Shanghai Science \& Technology Committee (No. 11JC1405500).

[1] S. Park, R. Ruoff, Nat. Nanotechnol. 4 (2009) 217-224.

[2] A.K. Geim, K.S. Novoselov, Nat. Mater. 6 (2007) 183-191.

[3] C. Lee, X.D. Wei, J.W. Kysar, J. Hone, Science 321 (2008) 385-388.

[4] A.A. Balandin, S. Ghosh, W. Bao, I. Calizo, D. Teweldebrhan, F. Miao, C.N. Lau, Nano Lett. 8 (2008) 902 907.

[5] K.I. Bolotin, K.J. Sikes, Z. Jiang, M. Klima, G. Fudenberg, J. Hone, P. Kim, Solid State Commun. 146 (2008) 351-355.

[6] D.B. Miracle, Compos. Sci. Technol. 65 (2005) 25262540.

[7] S.R. Bakshi, D. Lahiri, A. Agarwal, Int. Mater. Rev. 55 (2010) 41-64.

[8] C. Xu, X. Wang, J.W. Zhu, J. Phys. Chem. C 112 (2008) 19841-19845.

[9] V. Singh, D. Joung, L. Zhai, S. Das, S.I. Khondaker, S. Seal, Progr. Mater. Sci. 56 (2011) 1178-1271.

[10] C.B. Liu, K. Wang, S.L. Luo, Y.H. Tang, L.Y. Chen, Small 7 (2011) 1203-1206.

[11] H.Y. Song, X.W. Zha, Commun. Theor. Phys. 54 (2010) 143-147.

[12] Z.P. Xu, M.J. Buehler, J. Phys.: Condens. Matter. 22 (2010) 485301.

[13] A. Smolyanitsky, V.K. Tewary, J. Phys.: Condens. Matter. 23 (2011) 355006.

[14] L. Jiang, Z.Q. Li, G.L. Fan, D. Zhang, Scripta Mater. 65 (2011) 412-415.

[15] K.S. Novoselov, A.K. Geim, S.V. Morozov, D. Jiang, Y. Zhang, S.V. Dubonos, I.V. Grigorieva, A.A. Firsov, Science 306 (2004) 666-669.

[16] T. Zhou, F. Chen, K. Liu, H. Deng, Q. Zhang, J. Feng, Q. Fu, Nanotechnology 22 (2011) 045704.

[17] H.C. Schniepp, J.L. Li, M.J. McAllister, H. Sai, M. Herrera Alonso, D.H. Adamson, R.K. Prudhomme, R. Car, D.A. Saville, I.A. Aksay, J. Phys. Chem. B 110 (2006) 8535-8539.

[18] K.H. Liao, A. Mittal, S. Bose, C. Leighton, K.A. Mkhoyan, C.W. Macosko, ACS Nano 5 (2011) 12531258.

[19] L. Jiang, G.L. Fan, Z.Q. Li, X.Z. Kai, D. Zhang, Z.X. Chen, S. Humphries, G. Heness, W.Y. Yeung, Carbon 49 (2011) 1965-1971. 